\title{
A IMPORTÂNCIA DA "POTENTIA DEI ABSOLUTA" PARA A GNOSIOLOGIA DE GUILHERME DE OCKHAM
}

\author{
Antonio Raimundo dos Santos*
}

SÍNTESE - Ockham foi o medieval que mais se valeu da noção de potentia Dei absoluta. Cabe examinar o significado deste conceito no desenvolvimento da gnosiologia do autor, para quem, em Deus, deve-se recusar toda espécie de necessitarismo. Sob o aspecto gnosiológico o argumento serve tanto para fundamentar e justificar a proposição negativa como para a própria essência do conhecimento.

PALAVRAS-CHAVE - Guilherme de Ockham. Potentia Dei absoluta. Necessitarismo. Proposição negativa. Autonomia e especificidade do conhecimento.
ABSTRACT - Ockham was the medieval philospher who appropiated the conception of potentia Dei absoluta. The meaning of this concept is examined here in light of the development of his epistemology, according to which every kind of necessitarianism is refused in God. On an epistemological reading, this argument is used to found and justify a negative proposition, as well as for the very essence of knowledge.

KEY WORDS - Ockham. Potentia Dei absoluta. Necessitarianism. Negative proposition. Autonomy and specificity of knowledge.

No Prólogo ao Comentánio das Sentenças, ${ }^{1}$ Guilherme de Ockham elabora sua teoria geral da evidência do conhecimento humano. A primeira questão do Prólogo, "se é possível ao intelecto do peregrino ter, neste mundo, notícia evidente das verdades da Teologia", traz consigo a pergunta mais ampla "se a Teologia é, de fato, uma ciência". A questão é teológica, visto que posicionada no início de uma obra de Teologia (Comentário das Sentenças). Porém, o discurso que se segue não discute primordialmente a validade do conhecimento teológico, mas a evidência possivel no conhecimento das verdades teológicas. O conjunto de razões elaborado no decorrer desta questão, constitui-se numa autêntica teoria do conhecimento.

Pontificia Universidade Católica do Paraná - Curitiba.

O texto base utilizado e eventualmente citado é o GULLELMI DE OCKHAM. Scriptum in Librum Primum Sententiarum (Ordinatio). Prologus et Distinctio Prima. Ed. G. Gál, adlaborante S. Brown. Cura Instituti Fransciscani, Universitatis S. Bonaventurae, St. Bonaventure, N.Y., 1967. As citações que aparecem adiante acompanhadas do indicativo Tradução, referem-se a SANTOS, A. R.. Prólogo do Comentánio de Guilherme de Ockham às Sentenças, Questão 1a. Apresentação e Tradução. Dissertação de Mestrado. PUC-SP, fevereiro de 1996.

\begin{tabular}{|l|l|l|l|l|l|}
\hline VERITAS & Porto Alegre & v. 45 & n. 3 & Setembro 2000 & p. $361-368$ \\
\hline
\end{tabular}


Um dos tópicos reveladores da sutileza lógica e da convicção teológica presentes ao pensamento de Ockham é a utilização da noção de poder absoluto de Deus (potentia Dei Absoluta) como parte da argumentação gnosiológica. Ockham pretende provar que é possivel o conhecimento intuitivo intelectivo ser produzido independente do conhecimento intuitivo sensitivo.

A utilização do poder absoluto de Deus, como parte da argumentação científca e filosófica, aparece como uma prática intelectual expressiva em boa parte da história das idéias no Ocidente. L. Bianchi ${ }^{2}$ aponta que este recurso já era utilizado por Arquitas, Lucrécio e Cleoménes como meio de estimulação teológica. Está também presente no De Coelo, de Simplicius, nos comentários aristotélicos de Roger Bacon, de mestres averroístas colegas de Siger de Brabante, em autores contemporâneos e/ou influenciados pela condenação de 1277 promovida por Estevão de Tempier, tais como R. de Mediavilla, J. Buridano, N. Oresme. Ainda em J. Locke é Deus quem conduz o homem aos confins hipotéticos do cosmo para completar sua experiência intelectual do concreto...

Ao que parece, o argumento do poder absoluto de Deus desempenhou papel heurístico e analítico fundamental para a "física nova" do século XIV. É pouco provável, porém, a interpretação de que sua repetida aparição nas "experiências de pensamento" do século XIV, bem como a distinção entre potentia Dei absoluta e potentia Dei ordinata, tenham se dado em virtude da condenação de 1277, relativa a certas posições assumidas pelo aristotelismo averroísta. A utilização do poder absoluto de Deus pode também representar a possibilidade de liberação da imaginação científica, permitindo a solução de questões novas; a consideração de situações contrafatuais, a elaboração de "experiências de pensamento" sugestivas, a construção de modelos de realidade sutis e originais. Pode-se afirmar

"que a distinção entre potentia Dei absoluta e potentia Dei ordinata não é difundida como conseqüência e por causa da condenação de 1277, e que não foi um instrumento conceitual tipicamente 'nominalista'; foi, ao contrário, traçada no início do século XIII, e conheceu interpretações e usos os mais diversos. Não é mais possível lançar mão de equações cômodas,porém restritivas, do gênero condenação de $1277 \Rightarrow$ potentia Dei absoluta $\Rightarrow$ nominalismo $\Rightarrow$ crítica a Aristóteles".

Ainda conforme a análise de L. Bianchi, "a linguagem da potentia Dei absoluta ora indica a lógica da descoberta e da justificação e ora a retórica da argumentação científica". Com efeito, tem-se a impressão de que às vezes o argumento teve uma função heurística e analítica indispensável; outras vezes nada mais foi que uma técnica de persuasão, um esforço de dar interpretação drástica, intuitiva e realista a uma hipótese de estudo.

2 BIANCHI, L.. "Potentia Dei Absoluta": logique de la découverte ou rhétorique de l'argumentation scientifique? - IN - Knowledge and the Sciences in Medieval Philosophy. Proceedings of the Eighth International Congress of Medieval Philosophy, Helsinki, 1990. Publications of the Luther - Agricola Society.

4 BIANCHI, L.. op. cit., p. 139.

Idem. p. 141 
Na reflexão teológica de Guilherme de Ockham, o poder absoluto de Deus tem lugar fundamental, enquanto mostra afastamento radical do necessitarismo aristotélico. Ockham é um crente, e, a fidelidade ao "creio em Deus Pai Todo Poderoso..." é por ele aceito como o primeiro artigo do credo cristão.

Deus é o criador de todas as coisas e possui as idéias das criaturas. Tais idéias, porém, não são a própria essência divina, nem puros produtos mentais, mas as próprias coisas a serem criadas, enquanto conhecidas por Deus: a própria criatura é a idéia, que Deus pode produzir no ser pelo conhecimento intuitivo que possui das coisas criáveis.

Em Deus não há idéias universais, mas apenas idéias de coisas individuais. 0 processo de "ideação" não é ligado à essência divina e à sua necessidade: as coisas singulares são, portanto, "ideadas" por Deus com absoluta liberdade. E para a liberdade da vontade divina não pode haver qualquer obstáculo.

Esta concepção abre um espaço ilimitado para o poder divino, estabelecendo ao mesmo tempo a contingência própria e essencial das criaturas, com as quais Deus não tem qualquer compromisso necessário. Em outra parte de sua obra, Ockham explica que Deus pode atuar com poder ordenado (potentia Dei ordinata) e com poder absoluto (potentia Dei absoluta):

"Eis o sentido em que se deve entender aquela distinção: às vezes, a expressão "poder alguma coisa" significa poder segundo as leis ordenadas e instituídas por Deus; e destas entende-se que Deus pode fazê-las com poder ordenado. Outras vezes, entende-se poder como poder fazer tudo o que não implica contradição, quer Deus tenha decidido fazê-lo ou não. Pois Deus pode fazer muitas coisas que não quer fazer, como diz o Mestre na 43a. distinção do $1^{\circ}$ Livro das Sentenças. E destas coisas se diz que Deus pode fazê-las com poder absoluto. Também o Papa não pode fazer certas coisas, conforme as leis por ele estabelecidas, ainda que, absolutamente falando, possa.

Esta distinção prova-se pelas palavras do Salvador, em João 3: quem não renascer da água e do Espírito Santo não pode entrar no reino de Deus. Ora, Deus é igualmente poderoso agora quanto foi antes; e antes, alguns [homens] entraram no reino sem o batismo, como é patente a respeito dos meninos circuncidados do tempo da Lei, e falecidos antes de obterem o uso da razão; portanto, tal coisa ainda é possivel. Mas o que então era possível, segundo as leis instituídas, agora não é mais possivel, segundo a lei agora instituída, embora, absolutamente falando, seja possivel."

Observe-se que a liberdade absoluta da vontade divina não pode ser pensada como arbitrariedade: há, em Deus, certa obrigatoriedade. Esta, porém, não lhe advém de qualquer compromisso necessário com as criaturas, mas exclusivamente d'Ele próprio. De potentia absoluta, Deus pode tudo o que é logicamente possível e Seu único limite é aquilo que inclui contradição lógica; de potentia ordinata, Deus pode tudo o que não for contrário à Sua vontade positiva e racional.

Assim isolado das outras características divinas, o poder absoluto de Deus mostra-se apenas como um conceito hipotético, que, porém, para o teólogo Ockham, é fundamental como antídoto contra todo necessaritarismo pressentido na ordem natural do mundo criado. Com efeito, para Ockham, aquilo que não é logicamente necessário, poderia ser diferente do que é. 
A partir disto julga Ockham poder justificar a possibilidade do conhecimento intuitivo de algo não existente, embora tal não aconteça em nosso estado atual. ${ }^{6}$

Conforme já dito, para assegurar a evidência do conhecimento, Ockham parte da proposição e dos dois atos que a constituem, a saber, a apreensão dos termos (ato apreensivo) e o juízo que se segue (ato judicativo), retorna aos termos incomplexos e discute o que entende por conhecimento intuitivo e abstrativo, reduzindo o conhecimento, afinal, a algum saber intuitivo, um conhecimento imediato do sujeito a respeito do objeto. Juntamente com o saber intuitivo, ou imediatamente após ele, temos o conhecimento abstrativo do mesmo objeto ou fato individual. $\mathrm{O}$ conhecimento abstrativo não é menos próprio e nem menos simples que o conhecimento intuitivo. Porém, no domínio do conhecimento simples e referente a um só objeto, a primazia do conhecimento intuitivo é absoluta: o que não é conhecido intuitivamente não pode ser conhecido por um conceito singular abstrativo correspondente.

$O$ ato judicativo, por ser um ato intelectivo, supõe conhecimento intuitivo intelectivo dos termos que o compõem; supõe também, para ser evidente, conhecimento intuitivo sensitivo dos mesmos extremos, pelo menos como causas parciais. O conhecimento intuitivo sensitivo dos termos (ou coisas significadas pelos termos), é requerido como causa remota, e o conhecimento intuitivo intelectivo dos mesmos termos (ou coisas significadas pelos termos), como causa próxima suficiente, pois "[...] apenas a notícia intelectiva é suficiente para o juízo, a título de causa próxima, [...]"?

Abre-se aqui uma dependência a ser resolvida: pro statu isto, ou seja, em nosso estado atual de peregrinos, o conhecimento intuitivo intelectivo não se dá sem o conhecimento intuitivo sensitivo. E tal dependência, ao que parece, compromete a defendida subjetividade do ato de conhecimento evidente.

A solução apresentada consiste em distinguir o estado atual de peregrino do ser humano, de um estado possível, em razão do poder absoluto de Deus. Ockham aponta que

"[...] é patente a todas as autoridades que tais verdades contingentes não podem ser sabidas a respeito destes sensiveis, exceto quando estão sob o sentido, porque a notícia intuitiva intelectiva destes sensíveis, no atual estado, não pode ser tida sem a notícia intuitiva sensitiva deles. E portanto, a [notícia] sensitiva não é supérflua, ainda que somente a notícia intuitiva intelectiva fosse suficiente, se fosse possivel que ela se desse naturalmente no presente estado sem a notícia intuitiva sensitiva, assim como se dá nos anjos e na alma separada, onde para a notícia evidente de tais verdades não se requer alguma notícia intuitiva sensitiva, como se dirá depois"."

Ao primeiro estado, embora não suficiente e absoluto, o conhecimento intuitivo sensitivo não é supérfluo; no segundo, um estado comparado ao dos anjos e das almas separadas, o conhecimento intuitivo intelectivo seria absoluto e sufici-

cf. Scriptum in Librum Primum Sententiarum. op. cit., p. 38. (Tradução, p. 111). cf. Scriptum in Librum Primum Sententiarum. op..cit., p. 27. (Tradução, p. 97). Idem. p. 27. (Tradução, p. 97-98). 
ente para o conhecimento evidente, independente do conhecimento intuitivo sensitivo. Como conseqüência, pro statu isto, o conhecimento intuitivo intelectivo acontece originariamente pelo efeito da coisa em si mesma. O conhecimento abstrativo e $\mathrm{o}$ ato judicativo portariam por isso, a mesma depenđência. Mas, é possível dar-se o conhecimento intuitivo intelectivo por outra forma, isto é, pelo poder absoluto de Deus.

A introdução do poder absoluto de Deus na argumentação coloca a questão da possibilidade de conhecimento evidente sob nova perspectiva. Primeiro, por Seu poder absoluto, Deus criou o ser humano segundo essência singular própria, e capaz de captar o sensível por um conhecimento intuitivo intelectivo, absolutamente suficiente como causa dos juizos. É a ordem querida por Deus para o estado atual do ser humano. Segundo, Deus pode, por Seu poder absoluto, fazer com que a ordem natural, pela qual se vai da coisa ao conhecimento intuitivo em geral, ou do conhecimento intuitivo sensitivo se vai ao conhecimento intuitivo intelectivo, seja rompida, e causar imediatamente o conhecimento intuitivo intelectivo.

O recurso ao poder absoluto de Deus possibilita a conclusão visada pela gnosiologia de Ockham: 0 ato de conhecer é específico por si mesmo, subjetivo, verdadeiro e evidente, quer as coisas sejam, quer não sejam ("sive res sint, sive res non sint"); é independente do objeto e absoluto, uma vez que, pelo poder absoluto de Deus, pode ser relativo a nada, isto é relativo a coisa não existente. Diz Ockham:

“[...] toda coisa absoluta, distinta segundo o lugar e o sujeito, de outra coisa absoluta, pode, pelo poder absoluto de Deus, existir sem esta, porque não parece verossímil que, se Deus quiser destruir uma coisa absoluta existente no céu, necessite destruir uma coisa existente na terra. Ora, a visão intuitiva, tanto sensitiva quanto intelectiva, é uma coisa absoluta, distinta segundo lugar e sujeito, do objeto. Assim como, se vejo intuitivamente uma estrela existente no céu, esta visão intuitiva, quer seja sensitiva ou intelectiva, é distinta, quanto ao lugar e ao sujeito, do objeto visto; logo, esta visão pode permanecer estando a estrela destruída; logo etc."

A patente diferença entre o conhecimento exercido no estado atual do homem (pro statu isto, naturaliter, de facto), e o conhecimento considerado absolutamente, isto é, quando produzido pela alma criada na sua essência pelo poder absoluto de Deus e independente das circunstâncias ou estados possiveis que possam alterar sua atuação, permite que se estabeleça a possibilidade de independência do conhecimento intuitivo intelectivo em relação à coisa sensivel, bem como a independência do conhecimento intuitivo em geral em relação a qualquer causalidade que possa ser exercida pela coisa externa sobre ele.

9 Idem. p. 38-39. (Tradução, p. 112). É curioso notar como este exemplo de Ockham, formulado no século XIV, pode ser hoje, no século XX, como que por ironia da história, instrumentalmente verificado. Com efeito, sabemos pela Astronomia Contemporânea, que a luz de muitas das estrelas que hoje vemos (a visão intuitiva sensitiva da qual escreve Ockham) há muito não mais faz parte da estrela que a gerou. A estrela já se apagou [...] e no entanto, ainda a conhecemos... 
Consegue-se desta forma a especificação por si mesmo do ato subjetivo de conhecer, o que pode ser verificado através da possibilidade de um conhecimento intuitivo de uma coisa inexistente.

É o que se torna patente pela comparação entre a evidência do conhecimento da proposição afirmativa e a evidência do conhecimento da proposição negativa, resumida por Ockham na resposta à sétima dúvida:

"À sétima dúvida digo que pela-notícia intuitiva da coisa pode ser conhecido eviden-
temente que a coisa não é, quando não é, ou se não for. E quando se pergunta pelo
que será causado este juízo, pode se dizer que pode ser causado pela notícia intuitiva
da coisa. E quando se diz que ela deve causar efeito oposto se a coisa for, pode se di-
zer que não é inconveniente que alguma causa com outra causa parcial cause algum
efeito, e que, todavia, ela apenas, sem a outra causa parcial, cause o efeito oposto.
Portanto, a notícia intuitiva da coisa e a própria coisa causam o juízo de que a coisa é;
quando, entretanto, a coisa mesma não é, então a própria notícia intuitiva, sem esta
coisa causará o juízo oposto. Concedo, portanto, que não é a mesma a causa destes
juízos, pois a causa de um é a notí́cia sem a coisa e a causa do outro é a notícia com a
coisa, como com a causa parcial."

Se, por exemplo, o que temos é uma proposição afirmativa com um sujeito e um predicado ( $\mathrm{O}$ homem é racional), a evidência é garantida pelo retorno ao conhecimento intuitivo de "homem" e de "racional", correspondendo a evidência do complexo à evidência de cada termo incomplexo da proposição, e não a um terceiro conhecimento: o fato de ser (é), não é, propriamente falando, um termo da proposição; se o que temos é apenas uma proposição afirmativa, com um sujeito existente, o conhecimento de "homem" é suficiente para evidenciar que "homem é". Se, porém, tem-se uma proposição negativa, não é possivel basear sua evidência num conhecimento intuitivo natural, pois não estariam presentes os existentes singulares, causa remota do conhecimento intuitivo intelectivo. A evidência destes incomplexos só se daria de potentia absoluta Dei.

Com efeito, a proposição negativa contém um sujeito e/ou um predicado aos quais a existência real é negada. "A não é B" implica ou que "A não é" ou que "A é não $B$ ". Nenhum conhecimento intuitivo poderia ser naturalmente causado a partir de A ou de B, já que, no primeiro caso, "A não é", e no segundo caso, não se tem B, e sim "não B".

André de Muralt ${ }^{11}$ detalha esta conseqüência dizendo que

"à proposicão 'S é p', quer dizer $\mathrm{Sp}$, correspondem duas notícias intuitivas, causas da evidência da proposição; à proposição 'S é', quer dizer 'S', corresponde uma notícia intuitiva, causa da evidência da proposição, complexa quanto à linguagem, simples quanto à correspondência de seu único termo na realidade. Por outro lado, à proposiÇão 'S não é p', isto é 'S é não p', correspondem uma notícia intuitiva, causa da evidência do sujeito daquele predicado negativo, e, de potentia absoluta Dei, uma notícia intuitiva de uma coisa que não existe, causa da evidência da negação do predicado

10 Idem. p. 70-71. (Tradução, p. 152-153).

MURALT, A. de. op. cit., p. 139. 
daquele sujeito. À proposição 'S não é', isto é, 'não S', corresponde de potentia absoluta Dei, uma notícia intuitiva de uma coisa que não existe, causa da evidência da negação do sujeito da proposição negativa, complexa quanto à linguagem, simples quanto à correspondência de seu sujeito à não realidade".

O poder absoluto de Deus preenche, desta forma, o lugar da coisa inexistente, como causa eficiente para o conhecimento intuitivo dos termos da proposição negativa, aos quais, naturaliter, é negada a coisa como causa eficiente.

Ao que parece, fora desta interpretação, é difícil fundamentar ou justificar a evidência de uma proposição negativa. Evidentemente, não se trata do "milagre" pelo qual Deus todo poderoso dá ao intelecto humano a evidência da existência de algo que, de fato, não existe, mas de fundamentar logicamente a evidência da negação, que por si, elimina a causalidade das coisas. Note-se também que não há qualquer razão para que a evidência da afirmação seja diferente da evidência da negação: ambas são atos singulares do intelecto, quer a coisa seja, quer a coisa não seja. A evidência da proposição independe da existência ou inexistência da coisa, pois garante-se no intelecto.

Concluindo: o argumento do poder absoluto de Deus é, ao que parece, um argumento teológico, enquanto designa o modo sobrenatural (supranaturaliter) pelo qual Deus pode agir sobre o ato de conhecer natural (pro statu isto) do ser humano, substituindo por este Seu ato a causalidade eficiente natural do objeto, como demonstração de poder livre, cujo único limite é a contradição lógica; ${ }^{12}$ é, também, um argumento gnosiológico, enquanto define crítica e metafisicamente a condição intrínseca do conhecimento intuitivo como tal, confirmando a possibilidade da evidência do conhecimento, quer a coisa seja, quer não seja. E, por este lado, o argumento é necessário por dois motivos: primeiro, para fundamentar e justificar uma espécie particular de conhecimento, isto é, a proposicão negativa; segundo, para estabelecer a própria essência do conhecimento como autônomo e específico em si mesmo.

12 cf. Scriptum in Librum Primum Sententiarum. op. cit., pp. 58-60, "resposta à segunda dúvida". (Tradução, pp. 137-140). 